\title{
Thyroid disease diagnosed by point-of-care ultrasound after the induction of anesthesia: a case report
}

\author{
Masafumi Idei* (D) and Itaru Watanabe
}

Keywords: Point-of-care ultrasound (POCUS), Perioperative, Thyroid

\section{To the editor}

The importance of point-of-care ultrasound (POCUS) is increasingly recognized [1]. However, although POCUS has been used for perioperative evaluation of the heart, lungs, and airways [1-3], there are few reports on POCUS for perioperative evaluation of the thyroid. We report a case in which POCUS performed by an anesthesiologist in the operating room detected undiagnosed thyroid disease.

\section{Case presentation}

A 57-year-old woman was scheduled for spine surgery. Her preoperative examination was unremarkable, and there were no abnormal findings on blood tests, chest $\mathrm{X}$-ray, and 12-lead electrocardiogram.

Induction of anesthesia was performed with $200 \mu \mathrm{g}$ of fentanyl, $80 \mathrm{mg}$ of propofol, and $40 \mathrm{mg}$ of rocuronium. Oxygen, air, desflurane, and remifentanil were used to maintain anesthesia. While moving the patient to a prone position, we noticed that her left neck was slightly enlarged (Fig. 1). Using an ultrasound, we found that the left lobe of her thyroid gland was enlarged heterogeneously, with hypoechoic areas and microcalcifications (Fig. 2). The margin of the left lobe was somewhat irregular, and a mass approximately $1 \mathrm{~cm}$ in diameter with a calcification and an acoustic shadow was detected (Fig. 3).

An otolaryngologist was immediately consulted, and suspected chronic thyroiditis and papillary adenocarcinoma of the thyroid, and recommended a detailed postoperative examination. Thyroid hormone levels were not measured preoperatively.

* Correspondence: masafumi203@gmail.com

Yokohama Minami Kyosai Hospital, 1-21-1 Mutsuurahigashi, Kanazawa-ku, Yokohama 2360037, Japan

\section{Springer Open}

Because the patient had no symptoms suggestive of hyperthyroidism or hypothyroidism, no abnormalities on preoperative 12-lead electrocardiogram, and an uneventful course of anesthesia up to that point, we determined that the ultrasound findings would not affect her surgery and decided to continue as scheduled. Total operative time was $143 \mathrm{~min}$, and total anesthesia time was $210 \mathrm{~min}$. She was transferred to the ward after extubation, and the perioperative and postoperative course was unremarkable.

Six days after surgery, the patient underwent otolaryngologic examination and thyroid-specific laboratory testing. The anti-thyroglobulin antibody was high at $562 \mathrm{IU} / \mathrm{mL}$ (normal values $0-28 \mathrm{IU} / \mathrm{mL}$ ) and the antithyroid peroxidase antibody was also high, at $40 \mathrm{IU} /$ $\mathrm{mL}$ (normal values $0-16 \mathrm{IU} / \mathrm{mL}$ ). Her thyroid hormones (free triiodothyronine, free thyroxine, and thyroid-stimulating hormone) were within the normal range. Aspiration biopsy cytology revealed chronic thyroiditis (Hashimoto's disease) and papillary thyroid adenocarcinoma. The left lobe of the thyroid was resected for thyroid carcinoma 7 months after the first surgery, and the patient is currently being followed up in the otolaryngology department.

\section{Discussion}

Routine preoperative measurement of thyroid hormones and imaging of the thyroid is not currently the standard of care, and many patients may undergo surgery with undiagnosed thyroid disease, particularly in emergent cases.

Ultrasonography is commonly used in the diagnosis of thyroid disease [4]. In chronic thyroiditis (Hashimoto's disease), the gland is enlarged with heterogeneous hypoechoic areas, and the margin of the thyroid gland is 


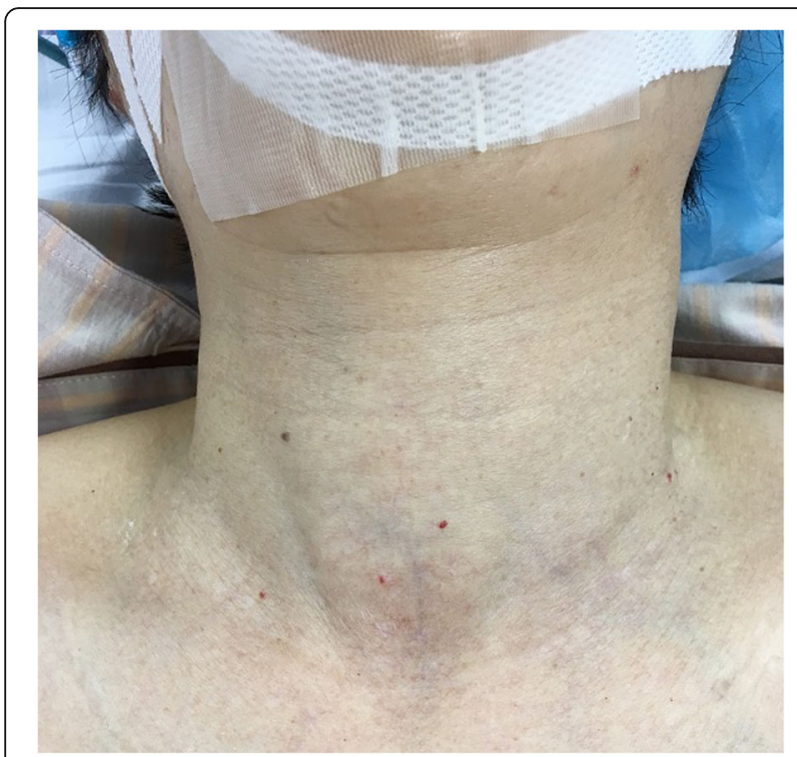

Fig. 1 Image shows slight left neck enlargement

irregular [5]. Furthermore, as Hashimoto's disease progresses, the thyroid gland atrophies and the echo level are attenuated [4].

In Basedow's disease, the thyroid gland is also enlarged, but the internal echo presents various images from hypoechoic to hyperechoic regions [4]. Another characteristic feature is enhanced blood flow of the suprathyroid artery, as seen on color Doppler [6].

For malignant tumors, such as papillary carcinoma, the outline of the entire thyroid gland is irregular and the internal tissue is heterogeneous [4]. Characteristic findings may include hyperechoic areas with minute calcifications, coarse acoustic shadows, and cervical lymph node metastases $[4,7]$.

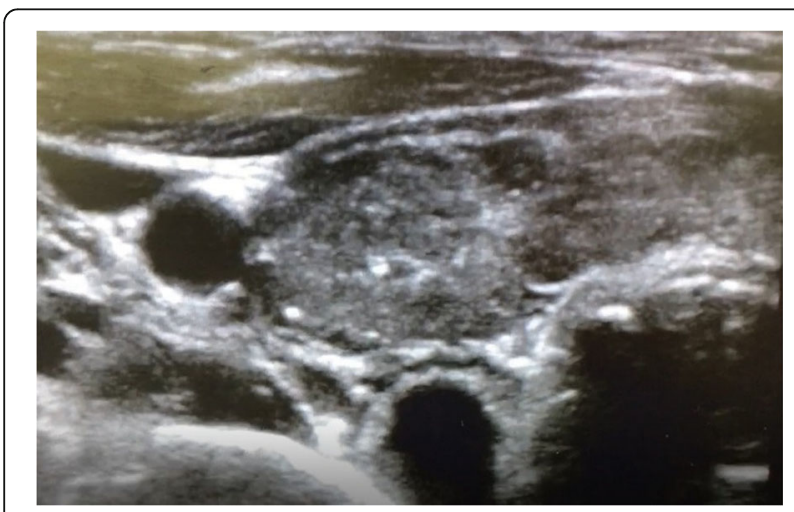

Fig. 2 Ultrasonography of the thyroid. The left lobe is heterogeneously enlarged with hypoechoic areas and calcifications

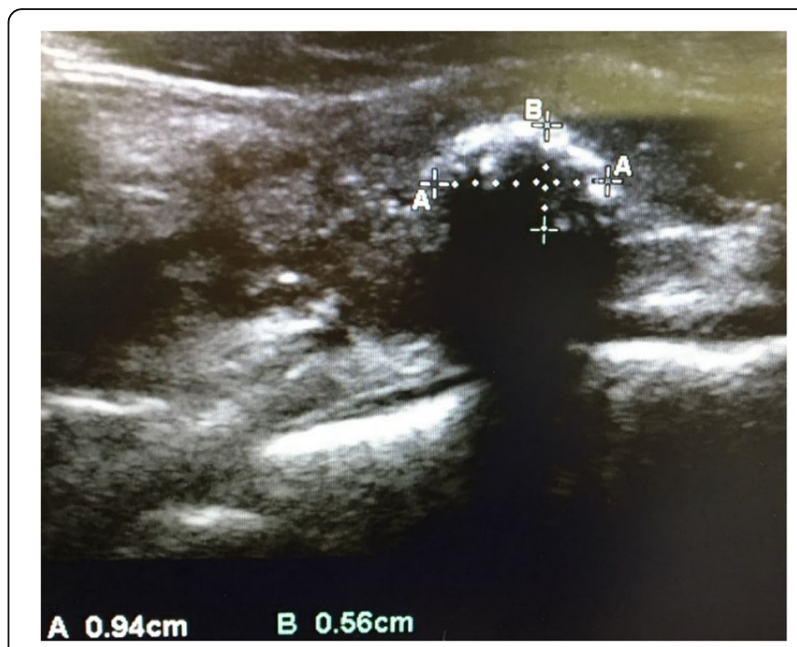

Fig. 3 Ultrasonography of the thyroid. A mass with a calcification and an acoustic shadow is observed in the thyroid

\section{Conclusions}

We present a case in which an anesthesiologist detected thyroid disease using perioperative POCUS. Because thyroid disease can influence perioperative care, we suggest that anesthesiologists should become proficient in the evaluation and diagnosis of the thyroid gland using POCUS.

\section{Abbreviations}

POCUS: Point-of-care ultrasound

\section{Acknowledgements}

We would like to thank our patient for providing to publish this case report. We would also like to thank Editage (www.editage.jp) for English language editing.

\section{Funding}

The authors declare that they have no funding.

\section{Authors' contributions}

MI wrote the draft of the manuscript. IW reviewed the manuscript. The final version of the manuscript was approved by all authors.

\section{Ethics approval and consent to participate} Not applicable.

\section{Consent for publication}

Written informed consent was obtained from the patients for publication of this case report and accompanying images.

\section{Competing interests}

The authors declare that they have no competing interests.

\section{Publisher's Note}

Springer Nature remains neutral with regard to jurisdictional claims in published maps and institutional affiliations.

Received: 20 February 2018 Accepted: 7 March 2018 Published online: 14 March 2018

\section{References}

1. Moore CL, Copel JA. Point-of-care ultrasonography. N Engl J Med. 2011; $364: 749-57$ 
2. Johnson DW, Oren-Grinberg A. Perioperative point-of-care ultrasonography: the past and the future are in anesthesiologists' hands. Anesthesiology. 2011;115(3):460-2.

3. Holm JH, Frederiksen CA, Juhl-Olsen P, Sloth E. Perioperative use of focus assessed transthoracic echocardiography (FATE). Anesth Analg. 2012;115(5):1029-32.

4. Masafumi K, Shinichi S. Japan Association of Breast and Thyroid Sonology. Thyroid ultrasound — a guidebook for diagnosis and management. 3rd ed. Tokyo: Nankodo; 2016.

5. Zosin I, Balaş M. Clinical ultrasonographical and histopathological aspects in Hashimoto's thyroiditis associated with malignant and benign thyroid nodules. Endokrynol Pol. 2013;64(4):255-62.

6. Karakas O, Karakas E, Cullu N, Demir Y, Kucukyavas Y, Surucu E, et al. An evaluation of thyrotoxic autoimmune thyroiditis patients with triplex Doppler ultrasonography. Clin Imaging. 2014;38(1):1-5.

7. Russ G, Bonnema SJ, Erdogan MF, Durante C, Ngu R, Leenhardt L. European thyroid association guidelines for ultrasound malignancy risk stratification of thyroid nodules in adults: the EU-TIRADS. Eur Thyroid J. 2017;6(5):225-37.

\section{Submit your manuscript to a SpringerOpen ${ }^{\circ}$ journal and benefit from:}

- Convenient online submission

- Rigorous peer review

- Open access: articles freely available online

- High visibility within the field

- Retaining the copyright to your article

Submit your next manuscript at $\gg$ springeropen.com 